\title{
Happiness and Values in the Formation of Personal Identity in Students of the Fifth and Sixth Grade at Primary School
}

\author{
Estefanía Gomis Chorro ${ }^{1, *}$, María Ángela Morales Fernández ${ }^{2}$, Raquel Gilar Corbii ${ }^{3}$ \\ ${ }^{1}$ Center for Early Childhood and Primary Education, CEIP La Rambla, Agost, Spain \\ ${ }^{2}$ Faculty of Teacher Education and Education, Autonomous University of Madrid, Spain \\ ${ }^{3}$ Department of Evolutionary and Didactic Psychology, University of Alicante, Spain
}

Copyright $@ 2017$ by authors, all rights reserved. Authors agree that this article remains permanently open access under the terms of the Creative Commons Attribution License 4.0 International License

\begin{abstract}
The objective of this research is twofold: first intending to assess the level at which students prioritize happiness; and second discerning how the experience of happiness affects the formation of their identity and their relationship with their environment, taking into account the values deduced from their perceptions, and understanding from where these values come, as well as how they are applied in their daily life. The findings indicate that students in fifth or sixth grade value happiness as a necessary aspect of life, derived from criteria such as health, and friends and family. The concept of happiness, however, is learned at home with parents and families.
\end{abstract}

Keywords Happiness, Students in Fifth Grade, Students in Sixth Grade, Personal Identity, Values, Inter-cultural Happiness

\section{Introduction}

In order to know the world, one integrates ideas and experiences. Learning that takes place in the classroom, however, is not always useful in life. In order to face daily challenges and improve one's life, it is necessary to implement simultaneously, the following: knowledge, concepts, feelings, perspectives, abilities, strategies, beliefs, procedures, attitudes, values, and the development of critical and creative thought. These factors create competence in an individual, which in turn allows the individual to problem solve in a successful and creative manner.

The concepts analyzed in this research are happiness, values, and personal identity as they pertain to students in the fifth and sixth grade. The concept of personal identity is extremely important in these grade levels, yet the authors find that little research has been carried out by educational institutions. Globalization and an ever-changing society necessitate that students be confident in developing personal identity, and surviving crisis and loss of personal identity. A sense of belonging and participation must be encouraged by the school in order to promote a positive and constructive social harmony among students.

The feeling of personal identity develops as human beings leave the "primary bonds" which link them to their mothers and to nature. The child, who intertwines its own identity with that of the mother, cannot say "I" nor does the child have need of the word. Only after the child conceives that the world is a separate, independent entity can the child attain the self-awareness necessary to recognize that he or she is a separate person. Consequently, one of the last words the child learns to use is "I" (Fromm, 1967). In the opinion of the authors, as educators, feelings of belonging and participation must be promoted in school in order to foster a constructive coexistence among students.

[1] Del Rosario Arenas Paz (2011) says that, from a psychological point of view, personal identity is what delineates "oneself" from "another one".

Se trata de un conjunto de rasgos personales que conforma la realidad de cada uno y se proyecta hacia el mundo externo permitiendo que los demás reconozcan a la persona desde su forma de ser específica y particular. La suma de las experiencias pasadas, presentes y futuras, es lo que le define como persona y le distingue del otro. La individualidad sólo es posible cuando se exterioriza la personalidad auténtica del ser humano, de manera tal que éste pueda reconocerse a sí mismo como parte de la humanidad en general y simultáneamente, como un ser único y diferente de los demás. (Cap. I, p.1)

[2] Erich Fromm (2000), contemplates identity as a necessity, a feeling that is essential. He professes that for humans, a sense of identity is so essential and imperative that 
humans cannot be healthy if they cannot find a way to satisfy it. According to the author, identity is an affective need, both cognitive (awareness of oneself and of the neighbor as different persons) and active (the human being must "take decisions" employing personal freedom and will). From the psychological point of view, identity is like the personality signature (Fromm, 2000).

This research takes into account not only individual works, but also the dynamic integration of socio-cultural processes and their effect on the concept of personal identity. In a review of published works about personal identity and values, the authors encountered numerous exploratory works in which three levels of identities are distinguished: the individual, the group and the community, underlining the published works by [3] Arfuch, 2002; [4] Martín and Barresi, 2003; [5] Morin, 2003 and [6] Peterson and Clark, 2003. Individual identity refers to each person as oneself, and group identity is defined as interpersonal relationships. By contrast, community identity goes beyond time and space to the individuals and the existing groups.

On the other hand, [7] Jimenez (2008) refers to values as principles which allow us to guide our behavior to grow as people. The author explains that these concepts are beliefs that help us to appreciate and choose some things over others, or a behavior instead of another one. They are also a source of satisfaction and fulfillment, since they provide guidelines to formulate goals and wishes, personal or collective. They reflect our interests, feelings and more relevant convictions.

That is why values refer to human needs and represent aspirations, dreams and hopes with an importance that is independent from the circumstances. Values become thoughts, concepts or ideas, but values are also the key to living in community with, and relating to, other people since they allow us to regulate our own behavior for the collective well-being and, in that manner, enable us to enjoy a harmonious coexistence.

[8] Seligman (2003), maintains that genuine happiness is not only possible but is far from dependent upon luck or genetic. Happiness can be developed, identifying and using many of the strengths and features that are already possessed. For the author, genuine happiness is based on the identification of what yields the best in ourselves and he believes that with the development of those aspects, people can noticeably improve their lives and the lives of those around them.

However, teaching students how to develop this emotional ability is not accounted for in school curriculum. The authors assert that the acquisition of happiness can be achieved by educating students how to appropriately manage their emotions, learning how to recognize and manage negative feelings while fostering and developing positive feelings.

Neuroscience indicates that happiness is a key element in the learning process. For [9] Mora (2003), joy is the awakening of the need for knowledge. This is the basis for the true nature of learning. The author adds that to understand in depth and from the perspective of how the brain works, is a basic teaching principle with which learning can be bettered /improved. This principle could be extended to upper university studies or to applied studies for business or scientific research.

The authors of this study assert, through their own experience, that students who feel happy in the classroom see their academic progress, their creativity and their confidence in themselves and others increased. Through the design of a curriculum that takes into account the development and management of happiness, the classroom would cease to be a place that generates competition and anxiety, instead becoming a laboratory of exploration and creativity. A place without doubt that would favor a more real and productive coexistence and, therefore, a more real and productive learning. Finally, they point out that the involvement of the entire educational community in these values would help to create an educational community aligned with a common identity. In this way, everyone would benefit.

The origin of this research occurred in a normal classroom setting, exploring the criteria used by the students when choosing new friends coming from different social and cultural backgrounds.

Our initial hypothesis was that students would choose children they perceived to be more socially successful and with a higher economical level. However, they chose happier children regardless of their origin or social background, based on the students' perception of who was happier in pictures. This unexpected response made us reflect on the importance of the concept and experience of happiness in our students and a questionnaire was developed to explore the concept of happiness and its impact on emotional development. The core of our study is, therefore, the concept and experience of happiness that our students have and, subsequently, we aim to explore how it impacts on the formation of their personal identity and the relationship with their social environment.

The parameters used in this qualitative research are: understanding of the natural, social and cultural environment, communication, inter-cultural happiness, attitudes and values, critical reflection and creative thinking.

\section{Methodology}

We used a qualitative methodology that consisted of the implementation of a questionnaire (Appendix 1) with six pictures of happy children from different social and cultural backgrounds and the following questions:

Q.1 Which of these children would you like to choose as friends? Why?

Q.2 What is happiness for you?

Q.3 Where have you learnt that the response you gave to Q2 is the source of happiness?

Q.4 From whom have you learnt that definition of happiness?

The stages in the process of this research are the 
following:

1st Stage:

1.1. Discussion and exploration of students' criteria for choosing new friends.

1.2. Observation of the mechanisms at work in the perception and functionality of the processes of personal identity and the values of the students.

1.3. Give the students the questionnaire.

\section{2nd Stage:}

2.1. Observation and analysis of the process of identification of the students.

2.2. Observation, identification and analysis of the values that are derived from this process of personal identity.

3rd Stage:

3.1. Obtain the results of the research.

3.2. Establish and understand functionality of the acquired values and their origin.

4th Stage:

4.1. To transmit these results to the students and discuss them in a group through reflection and critical and creative thinking.

5st Stage:

5.1. Elaborate further on the reflective and creative debate through the application of a Didactic Unit (see at the end of the conclusions).

\section{Tools/Instruments}

The tools used in this paper are: a questionnaire with pictures (Appendix 1) and open questions about the perception of the personal identity and values of the students in the fifth and sixth grades. The digital white-board is also used.

\section{Sample/Evidence}

The sample was a group of 45 pupils of the fifth and sixth grades who study in a school located in a rural area in the province of Alicante, Valencian Community (Spain). The village economy is based on marble industry and agriculture. The economic and cultural level of the families is medium average. $12.5 \%$ of these students were foreign, mainly English and Ecuadorian, who have attended the school since the start of their education and have no socialization issues.

\section{Review of Literature}

In the review of the works published on Personal Identity and Values, there is a great amount of bibliography in which three levels of identities are distinguished: the individual, the group and the community. There are three levels of amplitude but at the same time, three different qualitative types: individual identity concerns each person in itself, group identity is defined by real interpersonal relationships, while community identity, in principle, transcends in time and space to individuals and existing groups. However, we do not find published studies on the impact and influence that the concept of happiness and values can have on the formation of personal identity in Primary School students.

According to the DSM-IV (Diagnostic and Statistical Manual of Mental Disorders), individual identity is considered as a subjective feeling of unity in the person, liable to experiencing disorders (temporary or not) which can be pathological or normal (and temporary), whose forms and deviances are culturally specific. That is why it is evident that the concept of identity does not refer to homogeneity or continuity since every notion of identity scientifically implies change or dynamics.

According to [10] Kelly (1955), everyone makes a representation of themselves as integral members of the world. The whole of all these images is named by Kelly as the "system of constructs". Another model of the same genre belongs to [11] Allport (1954) who explains that the adhesions can be schematized as a set of concentric circles, which depart from a very specific nucleus that widens up into more general circles. At the centre is the family. The concentric circles represent consecutively: the outskirts, the city, the state/nation, race or ethnic group, mankind. The further away from the centre a circle is, the more abstract its content. Allport states that this loyalty diminishes in the measure that the distance increases in relation to the centre.

From a socio-cultural point of view, identity is constituted collectively, it is not static, it is actively in movement between the private and the public, between the personal and the cultural, between the past and the present. From this socio-cultural perspective, authors like [12] Gimeno (2000) emphasize the importance of education, specifically school attendance in the formation of the identity. Gimeno restudies [13] Hall (1996) to explain the identity of the self: the identity is the fixed, stabilized and coherent nucleus of the self, endowed with reason; a characteristic that is expressed in the coherence of conscious acts and consolidated from given conditions since the moment of birth and from some basic experiences that give the definite impression.

From a social epistemology, different authors speak about identity. Through the analysis of the human action in its context of development, [14] Vygotsky (1979) tried to show how different individual phenomena have their origins in the social activity. With the formulation of his socio-cultural method, we can study identity, because this approach provides the conceptual and methodological tools to understand the socio-cultural processes which configure the formation of identity. [15] Davis and Harré (1990) talk about identity from a socio-genetic perspective. For the authors, identity emerges only inside a web of relations of 'I' with 
others because in isolation, personal features are irrelevant.

Other authors talk about identity in a school context and its relation with adolescence and the choice of a degree: [16] Bloss (1992), [17] Vygotsky (1984) and [18] Erikson (1993). Bloss studied adolescence from a psychoanalytic approach and conceived identity as a reorganization of the emotional life in terms of intrinsic conflicts of risk and resolution. Likewise, Eriksson recognized the essential role of socio-cultural backgrounds in the formation of identity, for them identity is established in a process in the core of the individual and in the core of the community culture.

In relation to the concept of happiness, emotions and feelings perform a vital role in human beings and are absolutely linked to all areas of life. Emotions are present every day, at every moment; they are evident in our thoughts, through our actions, our behaviors, our facial gestures and body language. Lately, the need to have this emotional aspect present in the educative field is being considered, there is enough bibliography about emotional competences of our students but there are few works in this field about this subject. Besides this, there are few published works about the concept of happiness in the students at primary school.

Developmental psychology questions what and when children know about emotions, and how and what they understand about this process of regulation of emotions, in order to determine the optimal moments of educational intervention to enable students to learn to identity and control their emotions. This is a very important aspect for an optimal psycho-evolutionary development of children, an aim of education.

[19] Abarca M. (2002) highlights the emotional competence as a group of abilities that allows us to understand, express and regulate appropriately the emotional phenomena. He includes emotional consciousness, control of impulses, group work, taking care of oneself and others and so on. This facilitates the ability to cope better with life circumstances such as learning processes, interpersonal relationships, problem-solving, and adaptation to the context. [20] Bisquerra (2000) conducted exhaustive research about the classification of emotions, contents of consciousness and emotional regulation, the results of which make educational intervention more functional. From the early years we can teach emotional development and understand it as an educative process, continuous and permanent, that tries to promote the development of the emotional competences as an essential element in the integral development of the person [20-21] (Bisquerra, 2000, 2003).

[22] Koen Luyckx, Seth J. Schwartz, Luc Goossens, Wim Beyers, and Lies Missotten (2011) refer that [23] Côté and Levine (2002) distinguish among five identity strategies theorized as being common in late-modern societies. Resolvers are actively engaged in the process of forming an identity, fully capitalizing on opportunities provided within society, and motivated by a desire to optimize their potentials. Searchers are often driven by unrealistically high standards, rendering them unable to form a steady set of commitments.
They seem to be locked in a perpetual state of identity exploration and are in despair about their inability to enact or sustain commitments. In contrast, guardians have internalized the values of their parents or of society, providing them with a set of strict guidelines to move into adulthood.

[24] According to Arnett (2000), [25] Helson \& Srivastava (2001), identity searching can be associated with some distress, but it may also serve as the route to personal growth and hence should be viewed in the light of personal development or self-discovery

Within research on family socialization and parenting, there is a strong interest in the construct of psychological control, a parenting dimension highly relevant to the process of identity because it intrudes upon or impedes the adolescent's search for autonomy [26] (Barber, 2002).

[27] Luyckx, Soenens, Vansteenkiste, Goossens, and Berzonsky (2007) and [28] Beyers and Goossens (2008) conducted a longitudinal study on the four-dimensional identity model and its relationships to constructs such as supportive parenting and psychological control. Findings were in line with transactional models of socialization that emphasize the need to study both child and parent effects when examining parent-child relationships.

Humans are interested in their identity. Identity-relevant self-construal carry affective consequences [29] Leary, (2007). So people seek to construe themselves in ways that augment the pleasantness, or diminish the unpleasantness, of those consequences.

\section{Results and Discussion}

The origin of this research occurred in a normal classroom setting, exploring the criteria used by the students when choosing new friends coming from different social and cultural backgrounds. Aiming at exploring and understanding the preferences of the students in choosing their friends, the students are shown a selection of 6 images of children from different cultural and economic backgrounds who are having fun together and are asked which children they would choose as their friends and why (Q.1 Which children would you choose as your friends?). Our initial idea was that students would choose the image that shows children with more social success and a higher economic level.

\section{Q1. Which children would you choose as your friends?}

Firstly, 39\% of the students chose the picture with children belonging to a lower social and economic level because according to their criteria, "they are happier and they seem more fun". This choice makes them identify with this picture and with their perception that "happiness is necessary in life", understanding that happiness is a necessary criterion in their life. These answers made us think of the importance of this reflection and, consequently, three further questions were 
added to the questionnaire to gather more information and deepen understanding of the concept of happiness, from the students' point of view (Q2. What is happiness for you?; Q3. Where have you learnt that the response you gave to Q2 is the source of happiness? and Q4. From whom have you learnt that definition of happiness?).

Secondly, $26 \%$ of the students chose the picture that shows children who are of Romany descent, using the term "racism". Up to now, this term has not been mentioned in the classroom. According to the students, they would choose these children because "there is no racism between them, they respect each other and have fun together". This reflection is very important, because they associate the values of respect and fun as a form of prevention against racism.

Thirdly, 22.5\% of students chose the image with children similar to them because "they are like me". On this occasion, they have identified, in addition to the image of fun, with being a part of a group and talking to each other. Here, the value of communication is highlighted.

In fourth place, $13 \%$ of students chose the picture because the children in it "seem nice and fun". In the fifth and sixth places, both were equal with $9.6 \%$ students choosing the picture arguing that "there is respect between them and they have a lot of fun. Although they have nothing, they are very happy and have fun". The students highlight the value of happiness above materialistic value. Moreover, they identity with the actions performed in the images, i.e., sharing hobbies is a very important criterion when choosing friends.

\section{Q2. What is happiness for you?}

Remarkably, the highest number of students, $68 \%$, chose being healthy as the most important criterion in order to be happy. $48 \%$ of the students thought that having friends was the second most important criterion to achieve happiness. Only $26 \%$ of the students thought that to have a family was a necessary reason to be happy.

These results highlight the importance of friendship and feeling part of a group for the students of this age. This group belonging gives them security, allows them to feel confidence and it reinforces their personal identity. Although it is significant that the first criterion they associate with happiness is health.

It is also significant that only $13 \%$ of students answered with the criterion of "have the things I want", followed by only $9.6 \%$ with the answer "have love". $6.4 \%$ of the students think that happiness is having money, being with people they love, their family being well, and enjoying life. Finally, 3.2\% of the students chose criteria such as "to be kind, give money or donate blood, to know who you are, their parents not separating, no-one in their family dying, friends being happy, and to pass all subjects". These are barely significant results and somewhat dispersed.

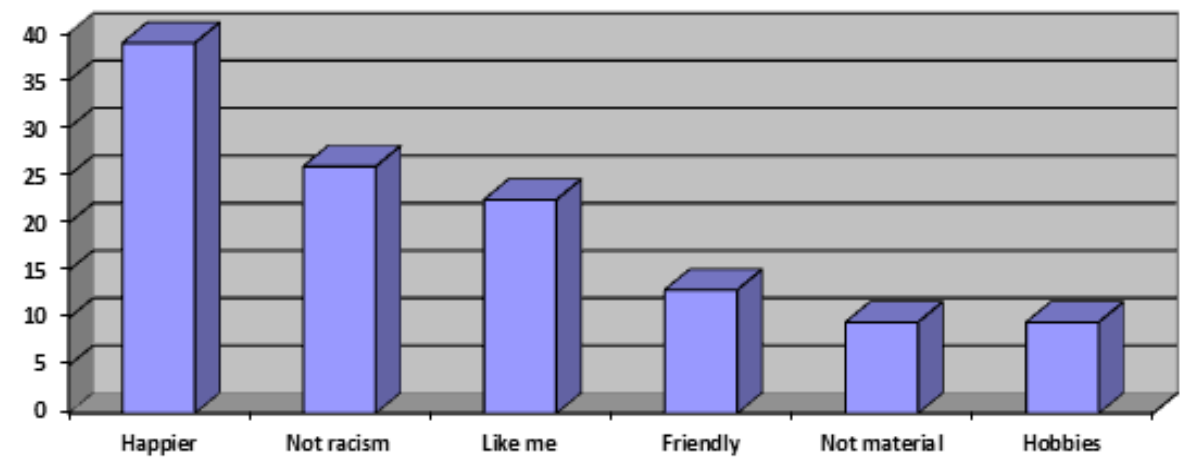

Graph 1. Which children would you choose as your friends?

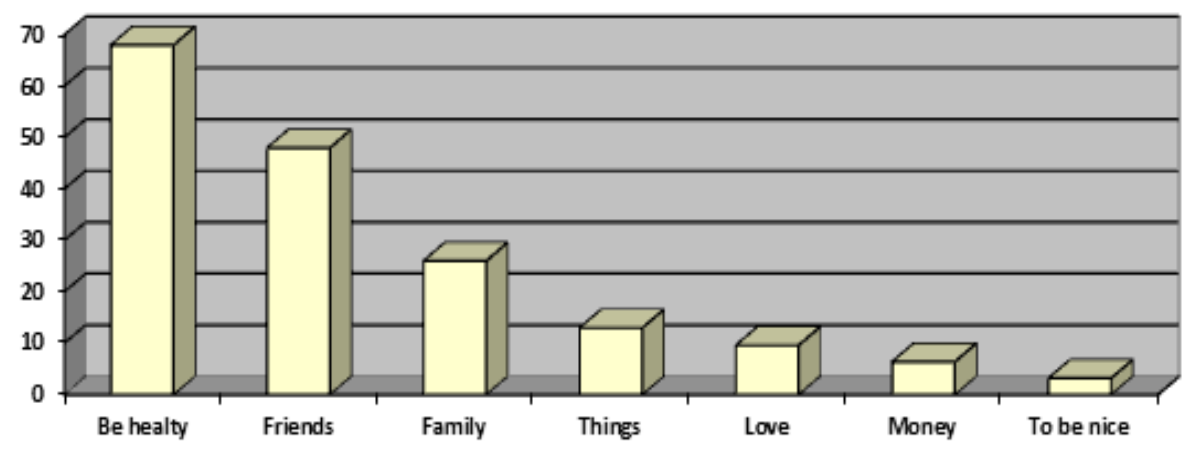

Graphic 2. What is happiness for you? 


\section{Q3. Where have you learnt that the response you gave to Q2 is the source of happiness?}

Most of the students, $84 \%$, responded that they have learnt the concept and perception of happiness at home, with their families. Considerably fewer students, only $26 \%$, said they have learnt it at school. $22.5 \%$ of the students said that they have learnt the concept and perception of happiness with friends because 'they help me to know when I am sad or happy'. These answers reinforce previous results in which the students of this age need the reference of their friends and the security of belonging to a group.

Finally, with low percentages of $6.4 \%$ and $3.2 \%$, respectively, the students name television and catechesis (Catholic education in preparation for First Communion) as the place where they have acquired their concept and perception of happiness.

\section{Q4. From whom have you learnt that definition of happiness?}

Similar to Q3, a high percentage of students, 80.6\%, answered that they have learnt the concept of happiness from their parents or family. If we add to this $80.6 \%$, the $16 \%$ of the answers giving grandparents as the source of learning this concept, we would have almost $100 \%$ of the answers. These results show us the importance of family in the emotional world of the students.

Far fewer students, 32\%, learn to be happy from their friends. It is surprising that in Q2, a high percentage of students, $48 \%$, respond that happiness is having friends, followed by $26 \%$ of having a family, however, the results of Q4 indicate that they learn this concept from their parents and family. Lastly, with only $13 \%$ and $6.4 \%$ respectively, the answers again place teachers in the last positions, together with television, as models to learn what happiness is.

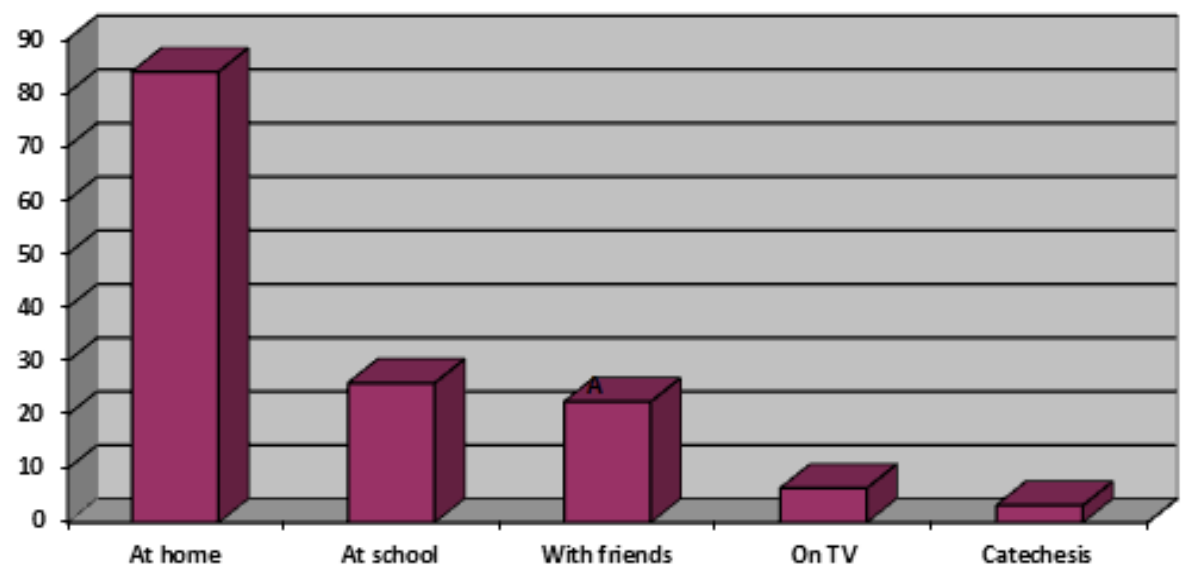

Graphic 3. Where have you learnt that the response you gave to Q2 is the source of happiness?

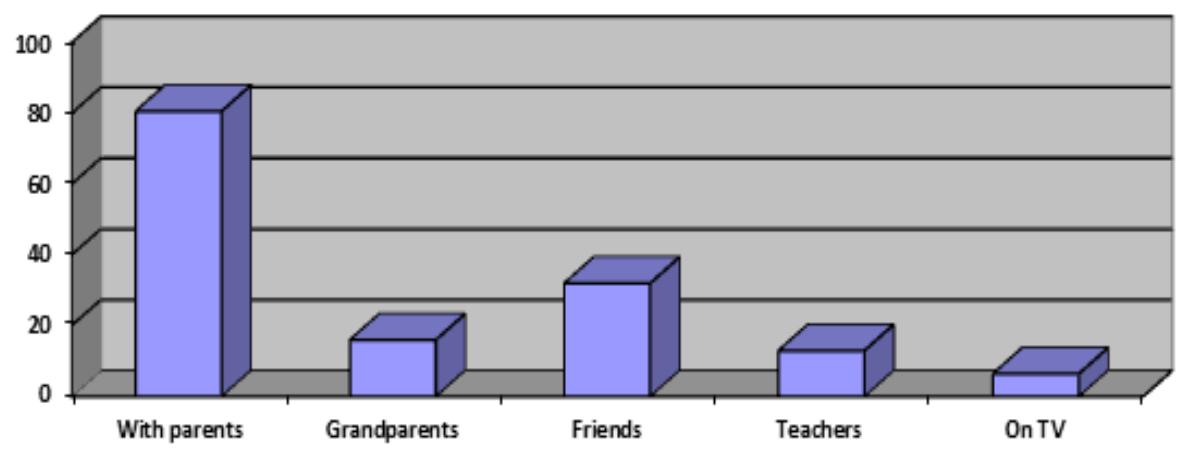

Graphic 4. From whom have you learnt that definition of happiness? 


\section{Conclusions}

Analyzing the results of the first question: 'Which children would you choose as friends', we can establish the order of the values of the students in the fifth and sixth grades at primary school:

1. Happiness is a necessity in life.

2. The values of respect and fun maybe a form of prevention against racism.

3. The value of communication is important in order to be happy.

4. Having fun is important in life.

5. Happiness is above material value. It is not necessary to have things to be happy.

6. Sharing hobbies is a criterion for choosing friends.

Regarding the second question 'What is happiness for you?', the analyzed results highlight the importance for the students of this age to have friends and to feel part of a group. This group belonging gives them confidence and strengthens their personal identity, although the students most significantly associate the criterion "health" with happiness. These answers may indicate that most of the students have their basics needs covered and they do not miss having materialistic things, since only a small number of students think that having things is necessary to be happy.

In relation to the third question: 'Where have you learnt that the response you gave to Q2 is the source of happiness?', the results obtained make us think that the majority of the students feel good in their families and they have them as referents and models for life. However, the students place the school as a model to learn how to be happy in a much lower position. This result would make us reflect about teachers, since it could suggest that too much attention is placed on curriculum and emotional education of the students is being neglected. The answers found in this third question reinforce the previous results in which the students of this age need the reference of their friends and the security of belonging to a group.

Regarding the last question: 'From whom have you learnt that definition of happiness?' the students highlight that their families make them feel happy and the experience of that feeling is what makes them learn the concept of happiness. The results obtained indicate that the students of this age associate being happy with having health and friends because, for them, it is necessary to have friends as models for personal identity, trust and belonging to a social group, but they learn the concept of happiness at home with their families, i.e., they learn to be happy by feeling the happiness that family life provides, in particular their parents and grandparents, in this order. These results show us the importance of the family in the emotional world of the students.
Once again, the students place in last positions the teachers, together with television as models for learning what happiness is. The analysis of these results should promote the curricular changes necessary to develop students' emotional competences.

In summary, fifth and sixth grade primary school students value happiness as a necessary aspect in life, associating criteria such as health, friendship and family in this order to achieve happiness. To be happy, they place more value on friends than family, however, the concept and perception of happiness is learnt at home with their parents and families. They learn to be happy by feeling happy and having their parents as models and their friends as a reference of identity and belonging. The students in the fifth and sixth grades consider happiness as the main value in human relationships, constituting a primary value necessary in their lives, an essential criterion for the choice of new friends, and to form their personal identity.

Finally, it should be pointed out that the students in the fifth and sixth grades think that 'fun, as an expression of happiness, prevents racism'. This reflection is very important for the development of programs to prevent racism which promote equality, justice and respect for diversity, Likewise, the results of this research suggest that it is necessary to update the teaching practice and equip teachers with new tools that develop students' feelings of happiness in order to, at last, establish shared values among the entire educative community.

\subsection{Didactic Proposals Identity and Values}

Following these results, a Didactic Unit is proposed to work out the concepts and criteria that the students have raised in the answers to the questionnaire, as well as the implication for teachers to be able to do and use in their own classrooms.

\subsection{Activities to promote critical thinking, reflection and creativity}

It is suggested that the discussion should not be limited to dealing with the cultural groups presented, since it is not a question of deepening the knowledge of the cultural group, but rather of the values and criteria that the students have expressed in the answers to the questionnaire. Creative thinking will be encouraged, trying to provide new and creative solutions to issues emerging from the debate.

\subsubsection{1st Activity: Video to discuss the concept of intercultural happiness}

Computer classroom: Video viewing to establish comparisons between different cultural manifestations. 
Ask students to explain similarities and differences between our culture and the other cultures shown in the video. Explain your criteria for being happy in different cultures. They must also select the most appropriate way to represent the information (outline, table, etc.)

\subsubsection{2nd Activity: Declaration of Human Rights. Values of respect against racism}

Analyze different articles of the Declaration of Human Rights. What rights do the students have in common with images of children from different social and cultural backgrounds? Which of them are fulfilled for them and which ones are fulfilled for each one of us? It is also suggested to consult Human Rights: thematic index.

Based on the answers given, they will be able to create a chart containing the similarities and differences that they believe exist between boys and girls of different social and cultural backgrounds.

\subsubsection{3rd Activity: Analyze the changes in society and} the place that their personal and social / cultural values occupy, recognizing their functionality and repercussions. The values of communication, intrinsic happiness above materialism, respect and generosity will be discussed and reflected upon

- Interpretation and representation of processes of historical change

- Analysis and interpretation of some works of art from different perspectives (sociological, iconographic ...) using various information about the historical context, the author, the public, etc.
- Search, analysis, interpretation and critical evaluation of information about societies or cultures other than their own from different sources of information (written, material, visual, etc.).

- Analysis and interpretation of cultural values in different societies.

- Comparison of cultural values with survival values. Are they the same, different, which are more necessary, what are their functions...? Explain your reasons.

\subsubsection{4th Activity: Synthesis of conclusions from a creative and artistic perspective.}

- Create a collage, mural, sculpture, poem and/or musical piece with or without lyrics....where they express their experiences as a conclusion and summary. This can be individual or in groups.

- $\quad$ Show these artistic works.

- Finally, families could be invited to an Open Day at the school to see these works. In addition, photos and texts of this work could be published on the school blog/web page, and could also be sent to the local and state newspapers.

\section{Acknowledgements}

We are very grateful to all pupils than have participated in this study, as well as the members of the school management for facilitating all work.

Special thanks to Katie Howarth for her invaluable help in translating this study.

\section{Appendix}

\section{QUESTIONNAIRE}

Name:

Q1. Which of these children would you like to choose as friends? Why?

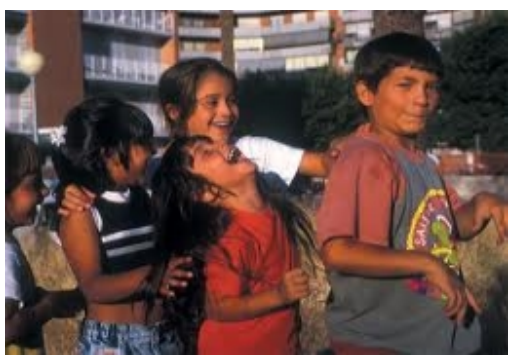

A

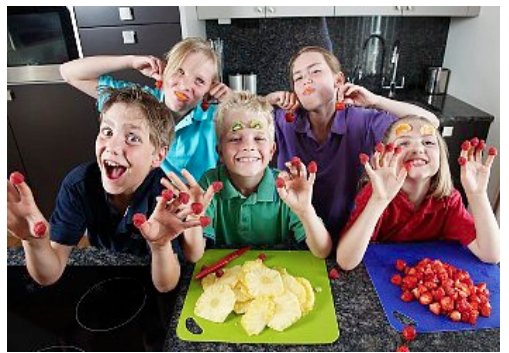

B

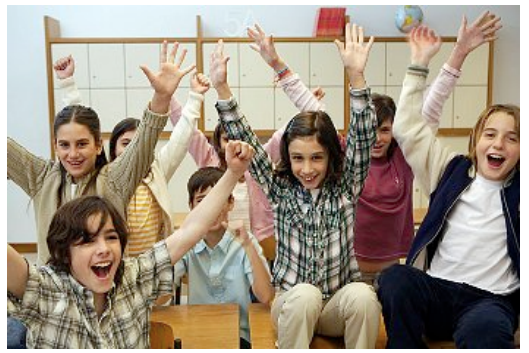

C 


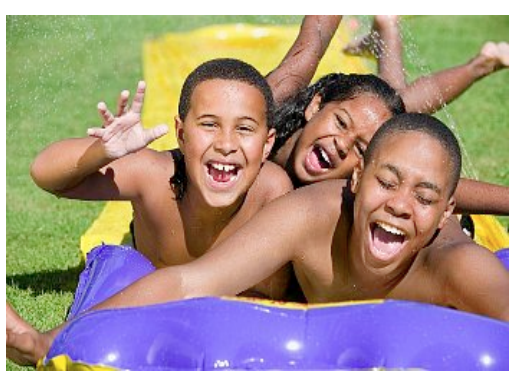

$\mathrm{D}$

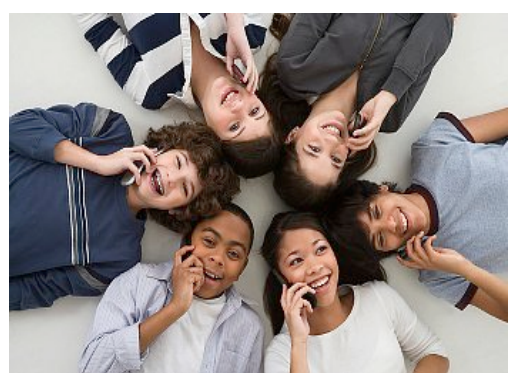

E

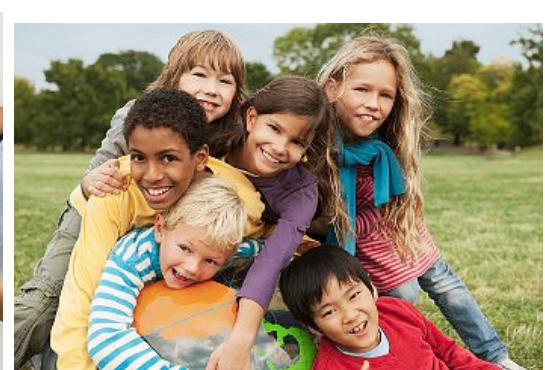

F

Q2. What is happiness for you?

Q3. Where have you learnt that the response you gave to Q2 is the source of happiness?

Q4. From whom have you learnt that definition of happiness?

\section{REFERENCES}

[1] Del Rosario Arenas Paz Revelado de huellas lofoscópicas en papel Monografías, 2011.

[2] Fromm, E., Del Tener al Ser. Ediciones Paidos Ibérica. 1a. Edición, 2000. Madrid, España. Pág. 38, 2000.

[3] Arfuch, L. Catanzarro, G., Di Cori, P. Pecheny, M. Robin, R., Sabsaym L., Silvestri, G. Identidades, sujetos y subjetividades. Bs. As., Prometeo, 2002.

[4] Martin, R. - Barresi, J. (Eds.). Personal Identity. Oxford, Blackwell, 2003.

[5] Morin, E. El método 5. La humanidad de la humanidad. La identidad humana. Madrid, Cátedra, 2003.

[6] [6] Peterson, B. - CLARK, E. (Eds.) Identity Dynamics and the Construction of Boundaries. Lund, Nordic Academic Press, 2003.

[7] Jiménez, J.C.,El Valor de los Valores. Cograf Comunicaciones, 2008.

[8] Seligman, M. E. P, La auténtica felicidad. Barcelona: Ediciones B., 2003.

[9] Mora, F., Neuroeducación. Alianza Editorial, 2013.
[10] Kelly; The psychology of personal constructs. Norton, New York, 1955.

[11] Allport, G. W., The historical background of modern social psychology. En G. Lindzey (Ed.), Handbook of Social Psychology, Vol 1, 3-56. Reading, Estados Unidos: Addison-Wesley, 1954.

[12] Gimeno, S.C., La educación obligatoria: su sentido educativo y social. Morata. Madrid, 2000.

[13] Hall, S. and y du Gay, P., Cuestiones de identidad cultural. Amorrortu editores Buenos Aires- Madrid, 1996.

[14] Vygotsky, L. S., El desarrollo de los procesos psicológicos superiores. Buenos Aires: Grijalbo, 1979.

[15] Davies, B. \& Harré, R., Positioning: the discursive production of selves. Journal for the Theory of Social Behavior. V. 20, pp. 43-63, 1990.

[16] Bloss, P., Psicoanálisis de la Adolescencia. Joaquín Mortiz, México, 1992.

[17] Vygotsky, L. S., Paidología del Adolescente. T: IV Pedagógica, Moscú. 1984.

[18] Erikson, Las ocho edades del hombre, en infancia y sociedad. Buenos Aires. Ediciones Hormé, 1993.

[19] Abarca Castillo, M., Marzo Ruiz, L., Sala Roca, L. La educación emocional en la práctica educativa de Primaria. Bordón. Revista de pedagogía, Vol. 54, N 4, 2002. 
[20] Bisquerra, R. Educación emocional y bienestar. Barcelona: Praxis, 2000.

[21] Bisquerra, R. Educación emocional y competencias básicas para la vida. Revista de Investigación Educativa, 2003, Vol. 21, n. 1, págs. 7-43, 2003.

[22] Luyckx, K., Schwartz, S.L., Goossens, L., Beyers, W., and Missotten, L. Identity Theory and Research. Chapter 4. Processes of Personal Identity Formation and Evaluation, 2011.

[23] Côté, J. E., \& Levine, C. G. Identity formation, agency, and culture: A social psychological synthesis. Mahwah, NJ: Erlbaum, 2002.

[24] Arnett, J. J. Emerging adulthood: A theory of development from the late teens through the twenties. American Psychologist, 55, 469-480, 2000.
[25] Helson, R., \& Srivastava, S. Three paths of adult development: Conservers, seekers, and achievers. Journal of Personality and Social Psychology, 80, 995-1010, 2001.

[26] Barber, B. K. Intrusive parenting: How psychological control affects children and adolescents. Washington, DC: American Psychological Association, 2002.

[27] Luyckx, K., Soenens, B., Vansteenkiste, M., Goossens, L., \& Berzonsky, M. D. Parental psychological control and dimensions of identity formation in emerging adulthood. Journal of Family Psychology, 21, 546-550, 2007.

[28] Beyers, W., \& Goossens, L. Dynamics of perceived parenting and identity formation in late adolescence. Journal of Adolescence, 31, 165-184, 2008.

[29] Leary, M. R. Motivational and emotional aspects of the self. Annual Review of Psychology, 58, 317-344. 2007. 